\title{
Preposition Pied Piping and Stranding in Academic and Popular Nigerian English Writing
}

\author{
Roseline Abonego Adejare ${ }^{1}$ \\ ${ }^{1}$ Department of Language, Arts and Social Science Education, Lagos State University, Lagos, Nigeria \\ Correspondence: Roseline Abonego Adejare, Department of Language, Arts and Social Science Education, \\ Lagos State University, Lagos, Nigeria. E-mail: abonego@yahoo.com
}

\author{
Received: May 18, $2021 \quad$ Accepted: June 20, $2021 \quad$ Online Published: June 23, 2021 \\ doi:10.5539/ijel.v11n4p40 URL: https://doi.org/10.5539/ijel.v11n4p40
}

\begin{abstract}
This paper examined preposition pied piping and stranding in academic and popular Nigerian English writing with a view to determining their pattern of occurrence. Preposition placement has not been studied in Nigerian English and in specific genres. The 160 246-word relevant component of ICE-Nigeria was the sub-corpus used, and the Systemic Theory guided the study. Analysed using a multi-layered qualitative approach, the data comprised 112 cases of pied piping, 64 of stranding and 4 of doubling. Pied piping was dominant over stranding in Academic Writing (78 percent v 22 percent), and stranding was 1.7 times more frequent in Popular Writing than in Academic Writing. Though evenly distributed in Popular Writing (44 each), pied piping was about twice as frequent as stranding in Popular Natural Sciences while stranding was virtually non-existent in Academic Natural Sciences. Whereas to-infinitive and passive clauses were stranding favourite sites $(21$ and 15 respectively), only in wh-relative clauses did pied piping operate and in which was the prominent sequence. In Academic Writing prepositions were pied-piped and stranded at an average of 3.83 and 1.82 per form respectively, but the rates were 3.31 and 3.1 in Popular Writing. Whereas in was the most pied-piped preposition and was 5.2 times more likely to be pied-piped than stranded, up was the most stranded form and its stranding relative to pied piping was infinitely more. Subtle differences in the genres' degree of formality explain the disparities in the distribution of pied piping and stranding in the sub-corpus analysed.
\end{abstract}

Keywords: preposition placement, preposition pied piping, preposition stranding, academic and popular writing, Nigerian English

\section{Introduction}

\subsection{Background}

The term preposition was derived from Latin praepenere, which means "put before" or "preceding position" (Chalker \& Weiner, 1994, p. 310, cited in Hoffmann, 2011, p. 76; Greenbaum \& Nelson, 2002, p. 71). It refers to small words such as in and on which, according to Curmie (1935, p. 87), cited in Huddleston (1984, p. 336), "indicates relation between the noun or pronoun it governs and another word, which may be a verb, an adjective or another noun or pronoun". The preposition invariably occurs with the noun phrase as its complement and heads the prepositional phrase, which functions primarily as adjunct in the clause structure. Although the preposition normally comes before its complement (e.g., "This is the house in which we live"), there are exceptions where the complement is moved to the front and the preposition is left alone by itself or "deferred" (e.g., "This is the house which we live in"). These two alternative structures respectively exemplify preposition pied piping (PP) and preposition stranding (PS) (Christophersen \& Sandved, 1969, pp. 79-82; Strang, 1969, p. 192; Quirk et al., 1985, pp. 657-665; Greenbaum \& Nelson. 2002, pp. 70-71).

Radford (2004, p. 163) traced the origin of the term "preposition pied piping" to Ross (1967), who coined it in analogy with the well-known fairy tale "The Pied-Piper of Hamelin". In Radford's (2004, p. 166) graphic description, the preposition "drags" its complement along with it when a wh-quantifier is moved to "spec-CP", as in "They asked [to whom he was referring]", "where the preposition to is pied-piped along with the wh-pronoun whom so that the whole prepositional phrase to whom moves to spec-CP position within the bracketed clause". In contrast, stranding entails prepositioning the wh-relative pronoun on its own, leaving the preposition "orphaned" as in "They asked [who he was referring to]". There are syntactic contexts which obligatorily demand stranding only, namely passive constructions, infinitive clauses, -ing clauses, 
non-wh-relative clauses, and comparative clauses. Wh-relative clauses however allow both stranding and pied piping, although there are restrictions too, such as that not occurring in infinitive clauses and whom considered more grammatical than who in pied-piped structures. The most easily stranded prepositions are those that are short, frequent, spatial, and have grammatical uses such as in, on, of, off, into, out of, onto, at, and with (Huddleston, 1984, p. 338; Quirk et al., 1985, pp. 663-674; Hoffmann, 2011, pp. 36-42).

Stranding is associated with speech and informal style, and is frowned upon by some grammarians. In contrast, PP "belongs to a more dignified and rhetorical style" and will therefore not likely occur in ordinary conversation, where it would "sound stiff and formal". Preferred in formal writing, PP is a development strongly rooted in the prescriptive tradition of the eighteenth century, during which the slogan "it is incorrect to end a sentence with a preposition" reigned supreme. This has been referred to as unwarranted rule against PS, described as the "unmarked option". Pied piping is only acquired through formal schooling, which makes it the unnatural option for English (Huddleston, 1984, p. 338; Quirk et al., 1985, p. 664; Hoffmann, 2011, pp. 75-78).

This is a study of PP and PS in academic and popular Nigerian English writing. It is therefore expected that features of the phenomenon highlighted in the preceding paragraphs will manifest in my data. It would, for instance, be interesting to find out how the formal $\mathrm{v}$ informal dichotomy between the two preposition placement options would play out, particularly as grammar teaching in Nigerian schools still forbids the stranding of prepositions, although it is not uncommon to find users strand prepositions even in formal writing. The outcome of this study would contribute to the ongoing description of Nigerian English as a variety of World English, and stimulate research into the characterisation of preposition pied piping and stranding in different genres and in other non-native varieties of English. It would, more significantly, redefine how prepositions generally are handled in the ESL classroom from the usage point of view.

\subsection{The Problem}

Preposition pied piping and stranding have attracted considerable attention in recent years, but the focus has been on frequency distribution and not on their behaviour in genres. Where the study is comparative and necessarily utilises native and non-native English corpora, it is invariably acquisition-oriented. No study has employed ICE-Nigeria or characterised the phenomenon in its constituent genres. Consequently, facts are lacking on how PP and PS occur in Nigerian English and in academic and popular Nigerian English writing. Given that formal and informal style are their two socially distinguishing features and that the genres themselves are samples of formal usage, it is surprising that the subject has not attracted the attention it deserves.

\subsection{Aims}

This study aims to examine pied piping and stranding as preposition placement options in academic and popular Nigerian English writing with a view to determining their pattern of occurrence. Its more specific objectives are to

a) identify and account for all instances of pied piping in academic and popular Nigerian English writing;

b) determine the distribution of preposition stranding in academic and popular Nigerian English writing;

c) compare and contrast preposition pied piping and stranding in academic and popular Nigerian English writing and account for variations in their distribution;

d) identify and account for deviant structures; and

e) extend the frontiers of investigation into the characterisation of Nigerian English.

\section{Literature Review}

This section reviews literature on PP and PS and articulates the theoretical framework for the current study. It proceeds as follows.

\subsection{Earlier Studies}

This review of earlier studies on PP and PS is in two parts. The first is on global outlook while the second is specifically on Nigerian studies.

\subsubsection{Global Outlook}

Hoffmann (2005) analysed PP and PS variation in English relative clauses by subjecting data extracted from ICE-GB to statistical GOLDVARB analysis. He found that the area of actual variation is tightly constrained due to factors such as syntactic functions of preposition placement, level of formality, and type of phrase. Thus, the presence of that and Ø in a relative clause categorically leads to PS, for instance. In his 2007 study of preposition placement in relative clauses, Hoffmann illustrated how a combination of corpus and introspection data allows a 
far more detailed analysis of the grammatical phenomenon than would have been possible with either approach, and reported in part that 49.5 percent of all PS occurs in relative clauses. Based on the popular idea that all grammatical knowledge is stored mentally as constructions, Hoffmann (2008) demonstrated how the analysis of various sources of empirical data can offer important insights into the mental organisation of the linguistic knowledge of a speaker of English. He outlined how PP and PS can be captured with Construction Grammar approaches like the Head-driven Phrase Structure Grammar (HPSG) model, and reported that PP was far more common than PS because PS is far more complex to process than PP.

The thrust of Hoffmann's (2011) book-length study was to investigate PP and PS in all possible clause types using combined corpus and introspection approaches. The corpus data was derived from ICE-GB and ICE-EA while the introspection data was obtained experimentally using production and grammaticality judgement tests. Construction Grammar's HPSG model underlined the study, which found, among others, that 33.5 percent of all preposition placement tokens were in clauses which normally require categorical PS and that finite that- and $\varnothing$-relative clauses were by far the most salient contexts in which speakers would come across obligatorily stranded prepositions. Far more stranded prepositions were exhibited by the Kenyan data, which also contained non-standard structures displaying no variations between PP and PS such as doubling, than by the British data.

Jack (2019) examined the acquisition of preposition placement in ESL and compared its distribution across different groups of writers in order to determine L1 influence on different types of relative clauses, among other objectives. Following Hoffmann (2011), he analysed the corpora for a wide range of variables and subjected same to a binary regressive analysis. Results showed that preposition placement was influenced by different input distributions depending on the level of proficiency, the type of clause, specific prepositions, and the usage frequency of lexical strings. Among the ten most frequently occurring prepositions, in ranked first in both fronting and stranding while of ranked second in fronting and sixth in stranding. Cappele (2001) did not set out to study preposition placement. However, in demonstrating that out of is a preposition he revealed that the complex preposition can occur in a pied-piped construction only. This is what qualifies the study for review. Rezai (2006) highlighted some issues pertinent to the acquisition of PP and PS by Persian speaking learners of English. Using a 50-item grammaticality preference task administered to 79 adult participants including 14 native speakers, he showed that there exists a correlation between output frequency and input saliency. In their study of the acquisition of PP and PS in interrogatives by Arab EFL learners, Almahammed, Ariff and Sidek (2015) reported a slight preference for PP (33.18 percent) over PS (31.38 percent), but noted that the difference is not statistically significant. While they identified salience as the only possible reason for PS since Arabic lacks it, L1 transfer was the reason adduced for PP because both English and Arabic have it.

\subsubsection{The Nigerian Research Scene}

There is a near absence of studies on PP and PS in the Nigerian research scene. The only known study to date is not on English but Yoruba (Ajayi, 2019). Nevertheless, this segment reviews those studies that are tangentially related to the subject preposition placement in English in the sense that they deal with aspects of preposition usage. Jibril (1991) used a 50-item linguistic questionnaire in which respondents were required to fill in the gap with an appropriate preposition as a study in language variation. Though the sentences were sourced from authentic Nigerian texts such as Amos Tutuola's My Life in the Bush of Ghosts, the study was not corpus-based. Based on the assumption that educated Nigerians deploy prepositions in ways and contexts different from Educated British English users, Ekundayo (2014) undertook a nation-wide survey of preposition usage to establish the popularity and acceptance of certain forms. The study adopted Intraference as theoretical underpin, employed qualitative analysis, and involved 100000 respondents comprising academics, administrators and final year undergraduates. Using the internet, questionnaires, observation, and spontaneous speeches as instruments, it found three categories of Intraference including superfluous use of prepositions, where two of the examples cited - it comprises of and this is the man to whom he gave the money to - pertain to PS and PP respectively.

In their study of the use of prepositions among undergraduate ESL learners Sotiloye, Bodunde and Olayemi (2015) reported that only 43.7 percent of students had an average mastery of preposition usage based on a 50-item-fill-in-the-gap test administered. The students' poor performance was attributed to the inherent nature of prepositions themselves and L1 interference. They pointed out that the Yoruba-English bilingual has a limited range of prepositions in their L1, which affects their perception and learning of English prepositions. Based on the assumption that learners are unable to differentiate between micro-lexical feature of prepositional and non-prepositional verb features and so insert prepositions after verbs indiscriminately, Ovu (2018) studied the redundant use of prepositions after transitive verbs (e.g., ${ }^{*}$ discuss about) using final year students of College of Education, Owerri. Guided by the Minimalist Approach, he tested both the frequency of usage and competence using two different five-point-rating scales and reported that a large number of students used verbs with 
prepositions in inappropriate contexts. Bamigbade (2012) analysed the linguistic style of conference fliers as a sub-genre of academic writing and reported that there was misuse of prepositions. None of the errors identified however relates to PP and PS. A more recent study of prepositions, though corpus-based and genre-focused, was on complex prepositions of the preposition-noun-preposition construction. It therefore had no use examining the variant use of prepositions in clause structure, which PP and PS represent (Adejare, 2020).

The foregoing points to why the current study has to be undertaken and the direction in which it should go. Although some studies were corpus-based, many were oriented towards acquisition and none examined preposition placement in genres. Outside three studies with some concern for which preposition should follow a given subclass of verbs in the Nigerian English research scene, no other one has any direct relationship with preposition placement. The present study is an in-depth analysis of PP and PS in academic and popular Nigerian English writing; it is not a study of preposition placement in different clause types, although it will benefit from the grammatical fact that the phenomenon occurs in clause structure. In addition, the combined corpus-introspection approach adopted by Hoffmann (2007 \& 2011) is theoretically and methodologically unsuitable for this dispensation.

\subsection{Theoretical Framework}

The theory on which this study is anchored is Systemic Theory. This is a corpus-based study of L2 English usage and the systemic grammatical theory is most suitable for handling data of this nature. Systemic Theory follows in the European functional tradition that studies language in relation to its functions or uses at both the formal and textual levels. It derives from J.R. Firth, for whom the idea of "system" is a functional paradigm, but its current state is credited to M.A.K. Halliday, who developed system into formal construct of a "system network". Systemic Theory is concerned with discovery of the nature and structure of linguistic form and its functional properties. It studies language as part of the social process and gives meaning a pride of place (Firth, 1957; Halliday, 1961, 1985; Berry, 1975; Halliday \& Matthiessen, 2004; Eggins, 2004). The notions of "system network" and "grammaticalisation", which are critical to the theory and which fundamentally pertain to the grammatical phenomenon under investigation, provide further justification for the choice of Systemic Theory as theoretical underpin. The links can be established right away.

A system network is a theory of language as choice, which means it represents a language or any part thereof as a resource for making meaning by choosing, such that "if a feature $a$ (and $b \ldots$ ) is present, then either $x$ or $y$ (or z...) is present" (Halliday, 1985, p. 27). Thus, preposition placement in English represents the feature $a$ while PP and PS, the available options from which users can choose, are respectively $x$ and $y$. According to Halliday and Matthiessen (2004, pp. 46-48), meanings in language can be construed either as lexicalisation or grammaticalisation. They reckoned that a language in which all meanings were construed lexically would be impossible to learn as a system and process as a text. Because there would be a word for every grammatical category (e.g., tense) and this would be unwieldy, it becomes necessary for some meanings to be grammaticalised. Grammaticalisation is therefore a process by which some things are turned into a grammatical system. One such type of organisation is as a closed system. Preposition placement belongs to a closed system in the same way as number in the English noun, and PP and PS are its two mutually exclusive terms. This makes it obligatory for there to be only one choice possible at any given time. So PP and PS cannot be jointly selected in the same clause structure in the same manner that singular and plural cannot be simultaneously chosen in a variable noun with respect to the number system. In this regard PS is the unmarked term (Hoffmann, 2011, p. 78) while PP is the marked term in the system of preposition placement. The foregoing strongly indicates that the systemic grammatical theory possesses the capacity to handle data for this study at its different stages of collection, analysis and interpretation.

\section{Method}

\subsection{The Corpus}

The 1010 382-word International Corpus of English Nigeria (ICE-Nigeria) forms the database. Downloaded using http://sourceforge.net/project/ice-nigeria as link, ICE-Nigeria comprises both spoken and written components, 32 text types and 902 separate files. The written component has 17 text types and 510 individual files grouped under appropriate file names, and this is where the actual corpus from which data for this study was extracted belongs. It is a sub-corpus of academic and popular writing consisting of 8 text types, 131 separate files and 160246 words. Four text types each belong to Academic Writing (AW) and Popular Writing (PW), and their word counts are respectively 80105 and 80141 . These and other facts are tabulated below. 
Table 1. Facts about the corpus

\begin{tabular}{lll}
\hline Text Type & File Name & Corpus Size \\
\hline Academic writing humanities (W2A) & AHum_01-11 & 20014 \\
Academic writing natural sciences (W2A) & ANsc 01-11 & 20017 \\
Academic writing social sciences (W2A) & ASsc 01-11 & 20008 \\
Academic writing technical (W2A) & ATec 01-11 & 20066 \\
Popular writing humanities (W2B) & PHum 01-20 & 20016 \\
Popular writing natural sciences (W2B) & PNsc 01-19 & 20037 \\
Popular writing social sciences (W2B) & PSsc 01-15 & 20022 \\
Popular writing technology (W2B) & PTec 01.33 & 20069 \\
Total & & 160246 \\
\hline
\end{tabular}

\subsection{The Participants}

Because there were 131 separate files there theoretically ought to be 131 participants for this study. But the exact number of participants was difficult to ascertain because authors' identities were not disclosed anywhere in the ICE-Nigeria document (The only exception was ANsc_01, which was probably an error.) and because some authors might have contributed more than one file. It is however safer to work with the assumption that 131 participants authored the 131 files dealing with the same number of subject matter. The participants comprise 68 males and 26 females, with the gender of 37 participants unindicated. Eleven ethno-linguistic backgrounds were associated with the participants as follows: Yoruba (37), Igbo (31), Urhobo (6), Edo (4), Efik (3), Esan (2), Hausa (2), Itsekiri (2), Tiv (2), Etsakor (1), and Igala (1). There was no information on the ethno-linguistic group of 40 participants. All the authors of the 44 files in AW were academics, but there was no information on the occupation of authors of the 87 files in PW, who were evidently not students or non-graduates. To have some insights into the contents of the 131 files, the title of each text type's first file is listed below (ASsc_01 lacks a title). Readers desirous of more detail are urged to visit http://sourceforge.net/project/ice-nigeria.

1) AHum_01: Equipping Indigenous Languages and Indigenizing Information Communication Technology: Principles, Processes and the Challenges

2) ANsc_01: Fluoroquinolone Use in Children: The Benefits and Risks

3) ASsc_02: The Problems with Existing Work on Terrorism

4) ATec_01: An Improved Solar Cabinet Dryer with Natural Convective Heat Transfer

5) PHum_01: Tragic Tendencies

6) PNsc_01: Traditional Preparation and uses of Maize

7) PSsc_01: Nigerians Lament Incidences of Child Sexual Abuse

8) PTec_01: Firm Launches Anti-Piracy Disks

\subsection{The Data}

All pied-piped and stranded prepositions in the 160 246-word sub-corpus of AW and PW constitute this study's data and they number 180. To facilitate and ensure its accurate retrieval, the 131 files contained in the eight text types were printed out. Each printed file was carefully read through to manually identify and mark every instance of PP and PS. These were counted and listed according to file name, text type, and genre. This was done for the two preposition placement options (See Tables 3 and 4). There occurred 112 cases of PP with 68 in AW and 44 in PW. There also featured 64 instances of PS, with PW having the higher figure of 44 and AW posting 20. Two instances of doubling (PP + PS), where both terms were selected in the same clause, were seen. Table 2 summaries the data and shows the specific text types from where each segment is derived. 
Table 2. Data summary

\begin{tabular}{llllll}
\hline Text Type & PP & PS & PP + PS & Total & Percentage \\
\hline AHum & 21 & 11 & 2 & 34 & 19 \\
PHum & 14 & 15 & 0 & 29 & 16 \\
ASsc & 23 & 1 & 2 & 26 & 14.4 \\
ATec & 16 & 7 & 0 & 23 & 13 \\
PNsc & 14 & 6 & 0 & 20 & 11 \\
PSsc & 9 & 11 & 0 & 20 & 11 \\
PTec & 6 & 12 & 0 & 18 & 10 \\
ANsc & 9 & 1 & 0 & 10 & 5.6 \\
Total & 112 & 64 & 4 & 180 & 100 \\
Percentage & 64 & 36 & 2 & & \\
\hline
\end{tabular}

\subsection{Analytical Procedure}

In order to adequately account for its different manifestations, a multi-layered qualitative approach was adopted for the analysis of data. This was guided by the understanding that both PP and PS have the clause structure as locus. The major criterion therefore was the nine clause types in which preposition placement occurs, namely wh- relative, that-relative, Ø-relative, $w h$-questions, to-infinitive, -ing participle, exclamatives, and comparatives (Hoffmann, 2011). Each marked token was therefore critically examined in its clause context to identify and note the clause type involved, after which two separate tables reflecting the syntactic peculiarities of each preposition placement option were drawn. These consist of a listing of the file name (e.g., AHum) with its file number (e.g., 01), followed by the pied-piped sequence (e.g., during which), or the stranded preposition in its clause context (e.g., to start with), in columns. Every identified and marked pied-piped and stranded preposition in every file, text type, and genre was so listed. Figures in each column were then added up to determine the total number of PP and PS reflecting each clause type. The total for AW and PW was similarly determined. This represents the first layer of analysis.

The second layer of analysis entailed examining each of PP and PS to reveal a different type of detail. All the 112 pied-piped prepositions were listed with their complements in order to determine the number and frequency of each sequence. This was done for each file, text type, and genre. Thereafter, the most frequent sequence and a few others were singled out for close scrutiny in the larger context of their clauses. This was aimed at identifying the specific textual functions they performed (e.g., defining terms), in addition to the primary meanings of the prepositions themselves. Where a preposition has two or more meanings, the frequency of each strain of meaning was also determined. This was particularly true of the string in which. All the antecedent nouns were also identified and accounted for. A similar analysis was undertaken for PS. Here, it must be acknowledged that, unlike PP where the complements are realised by a closed system item (the pronoun), the verb lexeme implicated in PS belongs to a class of open set items. Lexical heterogeneity and collocational restrictions ensured that there were far more verb lexemes to deal with than there were relative pronouns. Nevertheless, it was possible to identify and list all the stranded prepositions in the context of their immediate clausal affinities based on the frequency of each collocating verb lexeme. Consequently, the list of stranded prepositions is more heterogeneous and much longer than its pied-piped counterpart.

The third layer of analysis was comparative and multi-dimensional too. First, PP occurrence in AW and PW was compared, followed by PS. Then, the distribution of PP and PS as preposition placement options was compared, followed by a comparison of AW and PW in terms of PP and PS frequency, clause types, and the number and frequency of prepositional forms. Finally, all the pied-piped and stranded prepositions were listed in order to determine which ones straddled both placement options and which ones were restricted to either term. This made it possible to determine the total number of prepositional forms in the data, each form's frequency of occurrence, and the forms associated with each term and their relative frequency. Some statistics in the form of simple percentages aided the essentially qualitative analysis.

\section{Results and Discussion}

This presentation and discussion of results is in four main parts, namely pied piping, stranding, doubling, and comparison in that order.

\subsection{Preposition Pied Piping}

The 112 pied-piped prepositions were subjected to four different levels of analysis, the results of which are presented and discussed as follows. To facilitate the discussion, the full picture of PP occurrence in the 
sub-corpus is exposed in Table 3.

Table 3. Distribution of pied-piped prepositions in the sub-corpus

\begin{tabular}{|c|c|c|c|c|c|c|c|c|c|c|c|c|c|c|}
\hline & AW & & & & & & PW & & & & & $\mathrm{T}$ & & Freq \\
\hline \multirow[t]{4}{*}{$\mathrm{S} / \mathrm{N}$} & Prep. & A & A & A & A & $S$ & $\mathrm{P}$ & $\mathrm{P}$ & $P$ & $\mathrm{P}$ & $\mathrm{S}$ & o & $\%$ & $\mathrm{p}$ \\
\hline & $\&$ & $\mathrm{H}$ & $\mathrm{N}$ & $\mathrm{S}$ & $\mathrm{T}$ & $\mathrm{u}$ & $\mathrm{H}$ & $\mathrm{N}$ & S & $\mathrm{T}$ & $\mathrm{u}$ & $\mathrm{t}$ & & $\mathrm{m}$ \\
\hline & Comp. & $\mathrm{u}$ & $\mathrm{s}$ & $\mathrm{s}$ & e & $\mathrm{m}$ & $\mathrm{u}$ & $\mathrm{s}$ & $\mathrm{s}$ & e & $\mathrm{m}$ & $\mathrm{a}$ & & $\mathrm{w}$ \\
\hline & & $\mathrm{m}$ & $\mathrm{c}$ & $\mathrm{c}$ & $\mathrm{c}$ & & $\mathrm{m}$ & $\mathrm{c}$ & $\mathrm{c}$ & $\mathrm{c}$ & & 1 & & \\
\hline 1. & in which & 6 & 3 & 4 & 6 & 19 & 5 & 6 & 3 & 1 & 15 & 34 & 30.4 & 212.2 \\
\hline 2. & of which & 1 & 1 & 3 & 3 & 8 & 1 & 5 & 3 & 0 & 9 & 17 & 15.2 & 106.1 \\
\hline 3. & from which & 1 & 1 & 0 & 3 & 5 & 1 & 1 & 0 & 0 & 2 & 7 & 6.3 & 44 \\
\hline 4. & with which & 1 & 0 & 4 & 0 & 5 & 1 & 0 & 0 & 1 & 2 & 7 & 6.3 & 44 \\
\hline 5. & through which & 3 & 0 & 2 & 0 & 5 & 1 & 0 & 0 & 0 & 1 & 6 & 5.4 & 37.4 \\
\hline 6. & for which & 1 & 1 & 0 & 1 & 3 & 1 & 0 & 1 & 0 & 2 & 5 & 4.5 & 31 \\
\hline 7. & on which & 1 & 0 & 2 & 1 & 4 & 0 & 0 & 0 & 1 & 1 & 5 & 4.5 & 31 \\
\hline 8. & out of which & 0 & & 4 & 0 & 4 & 0 & 0 & 0 & 0 & 0 & 4 & 3.6 & 25 \\
\hline 9. & at which & 0 & 0 & 0 & 1 & 1 & 1 & 1 & 0 & 1 & 3 & 4 & 3.6 & 25 \\
\hline 10. & without which & 1 & 0 & 0 & 0 & 1 & 1 & 0 & 1 & 0 & 2 & 3 & 2.7 & 19 \\
\hline 11. & within which & 3 & 0 & 0 & 0 & 3 & 0 & 0 & 0 & 0 & 0 & 3 & 2.7 & 19 \\
\hline 12. & by which & 0 & 1 & 2 & 0 & 3 & 0 & 0 & 0 & 0 & 0 & 3 & 2.7 & 19 \\
\hline 13. & during which & 1 & 0 & 0 & 0 & 1 & 0 & 0 & 0 & 1 & 1 & 2 & 1.8 & 12.5 \\
\hline $14 .$. & to which & 0 & 0 & 1 & 0 & 1 & 0 & 0 & 1 & 0 & 1 & 2 & 1.8 & 12.5 \\
\hline 15. & in whom & 0 & 1 & 0 & 0 & 1 & 1 & 0 & 0 & 0 & 1 & 2 & 1.8 & 12.5 \\
\hline 16. & to whom & 1 & 0 & 0 & 0 & 1 & 0 & 0 & 0 & 0 & 0 & 1 & 0.9 & 6.24 \\
\hline 17. & below which & 0 & 1 & 0 & 0 & 1 & 0 & 0 & 0 & 0 & 0 & 1 & 0.9 & 6.24 \\
\hline 18. & to what & 0 & 0 & 1 & 0 & 1 & 0 & 0 & 0 & 0 & 0 & 1 & 0.9 & 6.24 \\
\hline 19. & from where & 0 & 0 & 0 & 0 & 0 & 1 & 0 & 0 & 0 & 1 & 1 & 0.9 & 6.24 \\
\hline 20. & among which & 0 & 0 & 0 & 0 & 0 & 0 & 1 & 0 & 0 & 1 & 1 & 0.9 & 6.24 \\
\hline 21. & around which & 0 & 0 & 0 & 0 & 0 & 0 & 0 & 0 & 1 & 1 & 1 & 0.9 & 6.24 \\
\hline 22. & by means of which & 1 & 0 & 0 & 0 & 1 & 0 & 0 & 0 & 0 & 9 & 1 & 0.9 & 6.23 \\
\hline \multirow[t]{4}{*}{23.} & after which & 0 & 0 & 0 & 1 & 1 & 0 & 0 & 0 & 0 & 1 & 1 & 0.9 & 6.24 \\
\hline & Total & 21 & 9 & 23 & 16 & 69 & 14 & 14 & 9 & 6 & 43 & 112 & 100 & 699 \\
\hline & $\%$ & 19 & 8 & 20.4 & 14.2 & 61 & 12.4 & 12.4 & 9.7 & 8 & 39 & 100 & & \\
\hline & $\begin{array}{l}\text { Freq. } \\
\text { pmw }\end{array}$ & 1049 & 400 & 1149 & 797 & 861 & 699.4 & 699 & 448 & 399 & 537 & 699 & & \\
\hline
\end{tabular}

\subsubsection{Distribution of Pied Piping in Clause Types}

As Table 3 clearly shows, 23 prepositions were pied-piped to their complements, all of which were $w h$-relative clauses except the $w h$-question in (2c) below. This is in line with existing reports that the $w h$-relative clause is the syntactic locus in which PP operates. So the complements are essentially relative pronouns, and these include the spatial adverb where used as a relative pronoun (Quirk et al., 1985, p. 442). No that- and Ø-relatives were seen. Two examples will suffice.

(1a) These are usually motivated by the grammatical configurations in which they function. (AHum_06 p. 1)

(1b) This is left for seven days after which a proper and permanent coated sheet is obtained. (ATec_08 p. 2)

\subsubsection{The Pied-Piped Prepositions, their Complements, and Antecedents}

Since prepositions and complements are jointly implicated in PP, they deserve separate attention in this consideration of the distribution of PP in clause types. Again, since a relative clause refers back to an antecedent nominal in the sentence, it becomes expedient to also examine what these nominals are and how they functioned.

\section{a) The Prepositions}

Nineteen individual prepositions were pied-piped. There occurred two complex prepositions out of and by means of that featured four times and once only. Preposition in was the most frequently pied-piped form and which was the collocating complement, fronted only twice before whom out of its 36 occurrences representing 32 percent of PP in the data. The closest form of was 53 percent less frequent with 17 indications, and it occurred with which only as complement. The rest featured less than ten times each and they include five with single occurrence each. The 19 pied-piped prepositions, all of which were fronted before the wh-relative pronoun which, are listed in 
descending order of magnitude with their frequency of occurrence thus: in (36), of (17), from (8), with (7), through (6), for (5), on (5), out of (4), at (4), to (4), within (3), without (3), by (3), during (2), below (1), among (1), around (1), after (1), and by means of (1). During and by means of are the only obligatorily pied-piped forms (Hoffmann, 2011, p. 72).

b) The Complements

Four relative pronouns functioned as complements and which was dominant, accounting for 95 percent of complements with 107 instantiations. The other three are whom with 3 occurrences (2.7 percent) and what and where with single occurrence representing 0.9 percent. The dominance of which as complement, which collocated with every one of the 19 piped-piped prepositions, can be explained by the fact that ideas or concepts rather than persons and personalities were the focus of writing. This also explains the rarity of whom. The following sentences illustrate the four relative pronouns that served as complements.

(2a) Bioabsorption is a process in which solids of natural origin are employed for binding the heavy metals. (ATec_03 p. 1)

(2b) The song has the potential of growing longer depending on the members of the family to whom the bride needs to be introduced. (AHum_10 p. 4)

(2c) To what extent do women practice exclusive breastfeeding? (ASsc_6 p. 2).

(2d) This is the point from where these elements of tragedy are drawn. (PHum_01 p. 1)

c) The Antecedents

There were 99 lexemes that featured as antecedent nominals to the 112 pied-piped sequences, and they comprise 94 nouns with 105 instantiations and 5 pronouns with 7. The pronouns are all (2), most (2), each (1), it (1), and some (1). Here is an example in context.

(3) ....and snacks, each of which were chosen as preferred meals... (ASsc_08 p. 3)

Twenty-four lexemes including two pronouns already listed occurred more than once. The yet-to-be identified noun lexemes are culture (4), one (3), process (3), month (3), area (2), configuration (2), way (2), case (2), language (2), extent (2), point (2), and disorder (2). The lexeme process serves as illustration because it featured as antecedent to three different pied-piped strings with different meanings. One is already shown in (2a).

(4a) The concept of rural development...connotes a process through which rural poverty is alleviated. (ASsc_07p. 1)

(4b) ....an active process by which beneficiaries or client groups influence... (ASsc_07p. 3)

It is not necessary to list the remaining 72 antecedent nouns since many of them will be encountered at some point in the course of this presentation. However, those that obligatorily demand PP, which incidentally include three already identified above, are illustrated in context.

(5a) There are two ways by which recurrence interval of rainfall can be carried out. (ANsc_10 p. 2)

(5b) ...the diligent manner in which the author has used ... (PHum_07 p. 1)

(5c) This is the point at which tragedy begins to command repulsive attention or acclaim depending on the make of the audience. (PHum_01 p. 1)

(5d) ... is primarily dependent upon the extent to which it contributes... (ASsc_07 p. 2)

(5e) The degree to which any stressful situation or event impacts your... (PSsc_11 p. 3)

A considerable syntactic distance sometimes existed between the antecedent and the pied-piped string as in (6), where the marked $\mathrm{x}+\mathrm{n}$ non-finite verbal group clause is intervening in-between.

(6) PROLOG is a language based on fast-order-predicate logic in which the specification of the problem... (ATec_09 p.3)

Among the antecedents were four animate nominals, one of which is in (7).

(7) And she gets pregnant...for a native sugar daddy, in whom she sees a father that has eluded her all her life. (PHum_11 p.1)

4.1.3 Comparative Distribution of Pied Piping in Academic and Popular Writing

Preposition PP was by far more frequent in AW than in PW as their 68 and 44 occurrences respectively representing 61 percent and 39 percent of the total 112 tokens attest. This gives an approximate ratio of 1:1.6 in 
favour of AW. This disparity shows even in the number of preposition-complement sequences in each genre. There were 19 in AW and 15 in PW, which represent 83 and 65 percent respectively of the 23 sequences listed in Table 3. Though the single-occurrence forms were evenly distributed between both genres, the complex prepositions were found in AW only. Moreover, in which, the most frequent pied-piped sequence, occurred at an approximate ratio of 1:1.7 in favour of AW. In contrast, of which was almost evenly distributed between the two genres.

The eight text types consisting the sub-corpus provide another level of comparison. From Table 3 it can be seen that PP was most frequent in ASsc and least occurring in PTec. Its frequency in descending order of magnitude is ASsc (23), AHum (21), ATec (16), PHum (14), PNsc (14), PSsc (9) ANsc (9), and PTec (6). The enclosed figures respectively represent $21.5,19,14.3,12.5,12.5,8,8$, and 5.4 percent of PP incidence in the data. Intra-discipline comparison further revealed that Academic Humanities Writing contained 11/2 times more PP than Popular Humanities Writing and that the phenomenon occurred in the Social Sciences at ratio 2:2.5 in favour of AW. With respect to the Natural Sciences it was ratio 1:1.6 in favour of PW. For technology writing the academic genre surpassed its popular counterpart by $21 / 2$ times (2:2.5).

What emerges from the foregoing is that even though AW has far more manifestations of pied-piped prepositions than PW, there are specific disciplines in which the trend is reversed as the Natural Sciences attest. Because the four disciplines can be categorised into Arts \& Social Sciences and Science \&Technology, it was possible to have further comparison and reveal more interesting features. Arts \& Social Sciences had a higher incidence of PP (67 or 60 percent) than Science \& Technology ( 45 or 40 percent) at a ratio of 3:2 in favour of the former. So why were prepositions less frequently pied-piped in scientific and technological writing than in humanities writing?

\subsubsection{Semantic and Textual Manifestations of Pied-Piped Prepositions}

Only the most frequent preposition and a few others are considered in this treatment of semantic and textual manifestations of pied-piped prepositions due to space constraint.

a) Preposition in with which as complement

With 34 occurrences in was the most fronted form as already seen and position was its dominant meaning, indicated 32 times (94 percent). Academic Writing accounted for 59.4 percent (19) while PW represent 41 percent (13). In meaning time was expressed twice (6 percent) in PW only. Pied-piped in with its complement which was almost always preceded by abstract nouns ( 30 or 88 percent). Only twice was the antecedent noun concrete; it was combined concrete and abstract in two. Here are illustrations of in meaning position and time.

(8a) The rig consists of a reservoir tank made up of transparent plastic material, in which stands the rise pipe... (ATec_05 p. 2)

(8b) Each of the kingdoms had settled in an area in which some inhabitants were already present. (AHum_07 p. 3)

(8c) This is the month in which Arabic language was practically born 1440 years ago. (PHum _19 p. 1).

Textually, 53 percent (18) of in which occurrence was in contexts where it served to describe or explain concepts. This function was slightly more frequent in AW (10) than in PW. Definition of terms and concepts represent 29 percent (10), and 80 percent of this was in AW (excluding AHum).

(9a) Unsafe abortion as defined by World Health Organisation is pregnancy termination in which either the operator or the environment and technique of operation failed to meet the basic standard required for safety. (ASsc_10 p. 1)

(9b) Experts say cervical cancer is caused by human papilloma virus (HPV). It is a disease in which cancer cells are found in the tissue of the cervix. (PNsc_15 p. 1)

(9c) An open fracture is one in which there is a break in the continuity of the skin and the underlying soft tissue. (ANsc_04 p. 1)

Only once did there occur definition of purpose of writing.

(10) This paper considers a situation in which a satellite down link signal is interfered by the signal from a terrestrial microwave network operating at the same frequency as the satellite system. (ATec_06 p. 1)

The sequence in which also featured in the description or explanation of processes and concepts, which represents 53 percent (18) and which was slightly more frequent in AW (10) than in PW (8). A sample from each genre will suffice.

(11a) The roots may be peeled, grated, fermented and fried with or without red palm oil into garri flour in which 
form it is mostly consumed in Nigeria. (ANsc_03 p. 2)

(11b) This simply means living a selfless life, in which you do not have anything to keep back... (PHum_07 p. 1)

The use of in which to identify geographical location was seen three times in PW, where the social unit community/society was almost always within the collocational span of the pied-piped sequence, and once in AW (See (8b) above). Assumptive and metaphorical roles featured once each. The excerpts below illustrate the three textual functions accordingly.

(12a) ...this is what is occurring in many modern societies in which corruption is a relatively minor social problem. (PSsc_07 p. 2)

(12b) In this study...we have assumed Z-R relationship proposed by Ajayi and Owolabi (1987) in tropical thunderstorm rain in the study in which $\mathrm{a}=461$ and $\mathrm{b}=1.31$ respectively. (ATec_06 p. 3)

(12c) Bandele-Thomas' novels are so carefully constructed around certain images and symbols, the sewage system in which Nuye Odum, Rayo and Baba Ayafe bath themselves. (AHum_02 p. 3)

b) Some other forms with their complements.

As already hinted, only an outline account of the semantic and textual functions of the less frequent preposition-complement sequences can be afforded at this point. It consists of listing each textual function and providing appropriate examples of the indicating forms.

i) Definition of Terms and Concepts

(13a) Language is man's greatest invention without which all other inventions... would have been impossible. (PHum_19 p. 4)

ii) Definition of Purpose (of writing)

(13b) The study was undertaken to present ways of helping out in the urban and rural electrification programmes in Nigeria, one way of which is by using photovoltaic technology. (ATec_04 p. 2)

iii) Identifying the Problem

(13c) The rate at which Nigerian women die after giving birth is alarmingly on the increase. (PNsc_07 p. 1)

iv) Descriptive and Explanatory Roles

(13d) There were 103 cases out of which 17 case notes had incomplete information and were excluded from the study. (ASsc_10 p. 2)

(All the occurrences of out of which were contextually negative.)

(13e) This is left for seven days after which a permanent and more coated sheet is obtained. (ATec_08 p. 2)

(13f) Generally there are two ways by which recurrence intervals of rainfall is carried out. (ANsc_01 p. 4)

$(13 \mathrm{~g})$...the leadership of the university should run an open government with which everyone can identify. (ASsc_11 p. 1)

v) Geographical /Social Location

(13h) All known religions of the world have their origins, beliefs and practices rooted in the cultures within which they grew. (AHum_05 p. 2)

(13i) "The physical effect of desertification...extends to the humid tropics, affecting production of tree crops like cocoa from which our country generate huge revenue", Okali stated. (PNsc_12 p. 3)

vi) Expression of Time

(13j) Each of the parties was asked questions about the other parties, their views about the construction of buildings in Nigeria...effectiveness and efficiency of their contributions to recent failures of buildings...the stages at which failures could occur... (ATec_10 p. 2) (See at which in (5c) above.)

(13k) This was confirmed by a source close to members of the organising committee who held a crucial meeting last week during which the two came up for deliberation. (PTec_19 p.1)

vii) Discussion of Findings

(131) It is remarkable that no males 40 years and above tested positive in this study as against females in whom positive result was obtained from 21 years. (ANsc_05 p. 3) 


\subsection{Preposition Stranding}

Although 64 cases of PS were recorded as already stated, there were actually 54 syntactic sequences based on the collocating verb lexemes. This means that, like the antecedent nominals implicated in PP, the verb lexemes rarely recurred. There indeed were only ten verb lexemes that got used twice each; the rest 44 had single occurrence. The stranded prepositions with their verbs are as shown in Table 4. Meanwhile, the rest of this presentation proceeds in the following order: clause context, frequency distribution, collocating verbs, and stranding in academic and popular writing.

Table 4. Distribution of stranded prepositions in the eight text types

\begin{tabular}{|c|c|c|c|c|c|c|c|c|c|c|}
\hline $\mathrm{S} / \mathrm{N}$ & Preps with Verbs & AHum & ANsc & ASsc & ATec & PHum & PNsc & PSsc & PTec & Total \\
\hline 1. & to start with & 2 & 0 & 0 & 0 & 0 & 0 & 0 & 0 & 2 \\
\hline 2. & to/can be attend(ed) to & 1 & 0 & 0 & 0 & 0 & 1 & 0 & 0 & 2 \\
\hline 3. & hail(s) from & 2 & 0 & 0 & 0 & 0 & 0 & 0 & 0 & 2 \\
\hline 4. & is referred to & 1 & 0 & 0 & 1 & 0 & 0 & 0 & 0 & 2 \\
\hline 5. & to pass through & 0 & 0 & 0 & 1 & 0 & 1 & 0 & 0 & 2 \\
\hline 6. & to catch up (on) & 0 & 0 & 0 & 1 & 0 & 0 & 0 & 0 & 2 \\
\hline 7. & is coming/come from & 0 & 0 & 0 & 0 & 1 & 1 & 0 & 0 & 2 \\
\hline 8. & to write about & 0 & 0 & 0 & 0 & 0 & 0 & 1 & 1 & 2 \\
\hline 9. & are brought /would want to bring up & 0 & 0 & 0 & 0 & 0 & 0 & 2 & 0 & 2 \\
\hline 10. & of signing/to sign up & 0 & 0 & 0 & 0 & 0 & 0 & 0 & 2 & 2 \\
\hline 11. & to start off & 1 & 0 & 0 & 0 & 0 & 0 & 0 & 1 & 1 \\
\hline 12. & to be reconciled with & 1 & 0 & 0 & 0 & 0 & 0 & 0 & 0 & 1 \\
\hline 13. & would usher in & 1 & 0 & 0 & 0 & 0 & 0 & 0 & 0 & 1 \\
\hline 14. & are....for & 1 & 0 & 0 & 0 & 0 & 0 & 0 & 0 & 1 \\
\hline 15. & will be put up & 1 & 0 & 0 & 0 & 0 & 0 & 0 & 0 & 1 \\
\hline 16. & must be disposed of & 0 & 1 & 0 & 0 & 0 & 0 & 0 & 0 & 1 \\
\hline 17. & to work with & 0 & 0 & 1 & 0 & 0 & 0 & 0 & 0 & 1 \\
\hline 18. & to set up & 0 & 0 & 0 & 1 & 0 & 0 & 0 & 0 & 1 \\
\hline 19 & to account for & 0 & 0 & 0 & 1 & 0 & 0 & 0 & 0 & 1 \\
\hline 20. & has to deal with & 0 & 0 & 0 & 1 & 0 & 0 & 0 & 0 & 1 \\
\hline 21. & can be relied upon & 0 & 0 & 0 & 1 & 0 & 0 & 0 & 0 & 1 \\
\hline 22. & stand for & 0 & 0 & 0 & 0 & 1 & 0 & 0 & 0 & 1 \\
\hline 23. & can think of & 0 & 0 & 0 & 0 & 1 & 0 & 0 & 0 & 1 \\
\hline 24. & live for & 0 & 0 & 0 & 0 & 1 & 0 & 0 & 0 & 1 \\
\hline 25. & to get away from & 0 & 0 & 0 & 0 & 1 & 0 & 0 & 0 & 1 \\
\hline 26. & to be walked on & 0 & 0 & 0 & 0 & 1 & 0 & 0 & 0 & 1 \\
\hline 27. & have turned into & 0 & 0 & 0 & 0 & 1 & 0 & 0 & 0 & 1 \\
\hline 28. & can avail (themselves )of & 0 & 0 & 0 & 0 & 1 & 0 & 0 & 0 & 1 \\
\hline 29. & look forward to & 0 & 0 & 0 & 0 & I & 0 & 0 & 0 & 1 \\
\hline 30 & to thank (God) about & 0 & 0 & 0 & 0 & 1 & 0 & 0 & 0 & 1 \\
\hline 31. & rumbled on & 0 & 0 & 0 & 0 & 1 & 0 & 0 & 0 & 1 \\
\hline 32. & frolicked with & 0 & 0 & 0 & 0 & 1 & 0 & 0 & 0 & 1 \\
\hline 33. & are forced upon & 0 & 0 & 0 & 0 & 1 & 0 & 0 & 0 & 1 \\
\hline 34. & settle in & 0 & 0 & 0 & 0 & 1 & 0 & 0 & 9 & 1 \\
\hline 35. & interfered with & 0 & 0 & 0 & 0 & 0 & 1 & 0 & 0 & 1 \\
\hline 36. & to stick in & 0 & 0 & 0 & 0 & 0 & 1 & 0 & 0 & 1 \\
\hline 37. & suffered from & 0 & 0 & 0 & 0 & 0 & 1 & 0 & 0 & 1 \\
\hline 38. & should not be toiled with & 0 & 0 & 0 & 0 & 0 & 0 & 1 & 0 & 1 \\
\hline 39. & ...doesn’t know of & 0 & 0 & 0 & 0 & 0 & 0 & 1 & 0 & 1 \\
\hline 40. & to mentor and follow up & 0 & 0 & 0 & 0 & 0 & 0 & 1 & 0 & 1 \\
\hline 41. & to come by & 0 & 0 & 0 & 0 & 0 & 0 & 1 & 0 & 1 \\
\hline 42. & need to be scaled up & 0 & 0 & 0 & 0 & 0 & 0 & 1 & 0 & 1 \\
\hline 43. & to mess up & 0 & 0 & 0 & 0 & 0 & 0 & 1 & 0 & 1 \\
\hline 44. & are catered for & 0 & 0 & 0 & 0 & 0 & 0 & 1 & 0 & 1 \\
\hline 45. & must be compensated for & 0 & 0 & 0 & 0 & 0 & 0 & 0 & 1 & 1 \\
\hline 46. & to communicate across & 0 & 0 & 0 & 0 & 0 & 0 & 0 & 1 & 1 \\
\hline 47. & ...preyed upon & 0 & 0 & 0 & 0 & 0 & 0 & 0 & 1 & 1 \\
\hline 48. & have seen...through & 0 & 0 & 0 & 0 & 0 & 0 & 0 & 1 & 1 \\
\hline 49. & are speaking to & 0 & 0 & 0 & 0 & 0 & 0 & 0 & 1 & 1 \\
\hline 50. & is heading to & 0 & 0 & 0 & 0 & 0 & 0 & 0 & 1 & 1 \\
\hline 51. & ...believe in & 0 & 0 & 0 & 0 & 0 & 0 & 0 & 1 & 1 \\
\hline 52. & can be turned off /on & 0 & 0 & 0 & 0 & 0 & 0 & 0 & 1 & 1 \\
\hline 53. & (light) goes off & 0 & 0 & 0 & 0 & 0 & 0 & 0 & 1 & 1 \\
\hline \multirow[t]{2}{*}{54.} & have touched on & 0 & 0 & 0 & 0 & 1 & 0 & 0 & 0 & 1 \\
\hline & TOTAL & 11 & 1 & 1 & 7 & 15 & 6 & 11 & 12 & 64 \\
\hline
\end{tabular}




\subsubsection{Preposition Stranding in Relation to Clause Structure}

Of the nine syntactic contexts for PS in the clause structure, the $t o$-infinitive clause was the most prominent (21 or 33 percent), followed by passive constructions ( 15 or 23 percent). Relative clauses held 18 (28 percent) stranded prepositions altogether, distributed 3, 6 and 9 times among that-, wh-, and $\varnothing$ - clauses respectively. This is far less than the existing report that 49.5 percent of all PS occur in relative clauses (Hoffmann, 2007). It is not known why the relative clause was far less attractive in the sub-corpus used. Whereas no exclamatives occurred, -ing participle clauses and comparative clauses had 4 representations each, with wh-questions hosting 2 . The foregoing supports the earlier findings that the to-infinitive clause and passive constructions are the favourite syntactic contexts in which prepositions are most regularly stranded (Huddleston, 1984; Quirk et al., 1985; Hoffmann, 2011). Table 5 presents more detail.

Table 5. Preposition stranding in relation to clause structure

\begin{tabular}{|c|c|c|c|c|c|c|c|c|c|c|c|c|c|c|}
\hline \multirow[t]{5}{*}{$\mathrm{S} / \mathrm{N}$} & \multirow[t]{5}{*}{ Clause Type } & \multicolumn{5}{|c|}{ AW } & \multicolumn{5}{|l|}{ PW } & \multirow[t]{2}{*}{$\begin{array}{l}\text { Grand } \\
\text { Total } \\
\end{array}$} & \multirow[t]{2}{*}{$\%$} & \multirow[t]{2}{*}{$\begin{array}{l}\text { Freq. } \\
\text { pmw }\end{array}$} \\
\hline & & $\mathrm{A}$ & $\mathrm{A}$ & $\mathrm{A}$ & $\mathrm{A}$ & $S$ & $\mathrm{P}$ & $P$ & $P$ & $P$ & $\mathrm{~S}$ & & & \\
\hline & & $\mathrm{H}$ & $\mathrm{N}$ & $\mathrm{S}$ & $\mathrm{T}$ & $\mathrm{u}$ & $\mathrm{H}$ & $\mathrm{N}$ & S & $\mathrm{T}$ & $\mathrm{u}$ & & & \\
\hline & & $\mathrm{u}$ & $\mathrm{s}$ & s & e & $\mathrm{m}$ & $\mathrm{u}$ & $\mathrm{s}$ & s & $\mathrm{e}$ & $\mathrm{m}$ & & & \\
\hline & & $\mathrm{m}$ & $\mathrm{c}$ & $\mathrm{c}$ & $\mathrm{c}$ & & $\mathrm{m}$ & $\mathrm{c}$ & $\mathrm{c}$ & $\mathrm{c}$ & & & & \\
\hline 1. & $W h$-Relative & 0 & 0 & 0 & 0 & 0 & 4 & 0 & 1 & 1 & 6 & 6 & 9.4 & \\
\hline 2. & That-Relative & 1 & 0 & 0 & 0 & 1 & 1 & 0 & 0 & 1 & 2 & 3 & 4.7 & \\
\hline 3. & $\varnothing$-Relative & 2 & 0 & 0 & 1 & 3 & 2 & 1 & 1 & 2 & 6 & 9 & 14.1 & \\
\hline 4. & Wh-Question & 1 & 0 & 0 & 0 & 1 & 0 & 1 & 0 & 0 & 1 & 2 & 3.13 & \\
\hline 5. & $T o$-infinitive & 5 & 0 & 1 & 3 & 9 & 3 & 1 & 5 & 3 & 12 & 21 & 33 & \\
\hline 6. & Passive & 2 & 1 & 0 & 3 & 6 & 1 & 2 & 4 & 2 & 9 & 15 & 23.4 & \\
\hline 7 & -ing participle & 0 & 0 & 0 & 0 & 0 & 0 & 1 & 0 & 3 & 4 & 4 & 6.3 & \\
\hline 8. & Exclamative & 0 & 0 & 0 & 0 & 0 & 0 & 0 & 0 & 0 & 0 & 0 & 0 & \\
\hline 9. & Comparative & 0 & 0 & 0 & 0 & 0 & 4 & 0 & 0 & 0 & 4 & 4 & 6.3 & \\
\hline & TOTAL & 11 & 1 & 1 & 7 & 20 & 15 & 6 & 11 & 12 & 44 & 64 & & \\
\hline & $\%$ & 17 & 1.6 & 1.6 & 11 & 31 & 23.4 & 9.4 & 17 & 19 & 69 & & & \\
\hline
\end{tabular}

\subsubsection{The Stranded Prepositions}

Fifteen propositional forms were stranded 64 times after 54 different verb lexemes. This means that each form theoretically collocated with more than one verb lexeme and that the number of stranded forms is actually fewer than the total frequency of stranding (See Table 4). One such form is from, which co-occurred with hail (2), come (2), get (away) (1), and suffer (1) at rates indicated by the enclosed figures. Of course, the three single-occurrence forms naturally had only one verb collocate (e.g., come by). When the 15 stranded prepositional forms were examined in relation to the nine stranding sites, a different form of detail was revealed, namely the rate of stranding per site. Table 6 displays the detail.

Table 6. Frequency of stranded prepositions in clause contexts

\begin{tabular}{|c|c|c|c|c|c|c|c|c|c|c|c|c|}
\hline \multirow[t]{2}{*}{$\mathrm{S} / \mathrm{N}$} & \multirow[t]{2}{*}{ Preps } & \multicolumn{2}{|c|}{ Clause Types } & \multirow[b]{2}{*}{$\varnothing-R$} & \multirow[b]{2}{*}{$W h-\mathrm{Q}$} & \multirow[b]{2}{*}{ To-inf. } & \multirow[b]{2}{*}{$\begin{array}{l}\text { Passive } \\
\text { Constr. }\end{array}$} & \multirow[b]{2}{*}{-ing Part. } & \multirow[b]{2}{*}{ Excl. } & \multirow[b]{2}{*}{ Comp. } & \multirow[t]{2}{*}{ Total } & \multirow[t]{2}{*}{$\%$} \\
\hline & & $W h-\mathrm{R}$ & That $-\mathrm{R}$ & & & & & & & & & \\
\hline 1. & up & 0 & 0 & 1 & 0 & 4 & 4 & 1 & 0 & 0 & 10 & 15.6 \\
\hline 2. & with & 2 & 0 & 0 & 0 & 4 & 2 & 0 & 0 & 0 & 9 & 14.1 \\
\hline 3. & to & 1 & 0 & 0 & 0 & 1 & 3 & 2 & 0 & 0 & 7 & 11 \\
\hline 4. & from & 0 & 0 & 4 & 0 & 1 & 0 & 1 & 0 & 0 & 6 & 9.4 \\
\hline 5. & for & 0 & 0 & 0 & 1 & 1 & 2 & 0 & 0 & 2 & 6 & 9.4 \\
\hline 6. & in & 1 & 1 & 0 & 0 & 1 & 0 & 0 & 0 & 1 & 4 & 6.3 \\
\hline 7. & on & 1 & 0 & 0 & 0 & 2 & 0 & 0 & 0 & 1 & 4 & 6.3 \\
\hline 8. & through & 0 & 1 & 0 & 1 & 1 & 0 & 0 & 0 & 0 & 3 & 4.7 \\
\hline 9. & of & 1 & 0 & 1 & 0 & 0 & 1 & 0 & 0 & 0 & 3 & 4.7 \\
\hline 10. & off & 0 & 0 & 1 & 0 & 1 & 1 & 0 & 0 & 0 & 3 & 4.7 \\
\hline 11. & about & 0 & 0 & 0 & 0 & 3 & 0 & 0 & 0 & 0 & 3 & 4.7 \\
\hline 12. & upon & 0 & 0 & 1 & 0 & 0 & 2 & 0 & 0 & 0 & 3 & 4.7 \\
\hline 13 & into & 0 & 1 & 0 & 0 & 0 & 0 & 0 & 0 & 0 & 1 & 1.6 \\
\hline 14. & by & 0 & 0 & 0 & 0 & 1 & 0 & 0 & 0 & 0 & 1 & 1.6 \\
\hline \multirow[t]{3}{*}{15.} & across & 0 & 0 & 0 & 0 & 1 & 0 & 0 & 0 & 0 & 1 & 1.6 \\
\hline & Total & 6 & 3 & 9 & 2 & 21 & 15 & 4 & 0 & 4 & 64 & \\
\hline & $\%$ & 9.41 & 4.7 & 14.1 & 3.13 & 33 & 23.6 & 6.3 & 0 & 6.3 & & \\
\hline
\end{tabular}


It was found that certain syntactic contexts were the preferred sites for some prepositions, whereas some others were more evenly distributed across the stranding sites. For example, it was noted earlier that the to-infinitive clause accommodated the most stranding. Of the 15 prepositional forms only 3 ( 20 percent) were not stranded in the structure of the to-infinitive clause and these are of, upon and into. The majority 12 (80 percent) were, and they include all the occurrences of about, 40 percent of up-occurrence, 44.4 percent of with, and the single instance of by and across. Here are contextual examples.

(14a) Since it may not be feasible or practicable to start off by offering all academic programmes and courses, there is need to carefully make a choice on those to start with. (AHum_08 p. 3)

(14b) The concave was perforated for the threshed seeds together with the chaff to pass through onto the stream of air from a fan to blow off the chaff. (ATec_02 p. 3)

(14c) It causes damage to the gum and holes on the teeth, giving room for more particles to stick in. (PNsc_17 p. 1)

The next clause type with the most stranding incidence is the passive construction. Again 44 percent of $u p-, 43$ of to-. 67 of upon-, and 33 of for-stranding took place there.

(15a) The book paints a true picture of the refugees and the horrors they are so atrociously forced upon by lending credence to the voices of the maimed men, women and children scarred and ravaged by war. (PHum_16 p. 4)

(15b) Most of the women would have lost a lot of blood before getting to the place where they can be attended to. (PNsc_07 p. 1)

$(15 \mathrm{c})$ For example, in the "cost" view model of network construction the need for reliable electricity at a regeneration point is viewed as a negative input that must be compensated for by either 1) costly construction... (PTec_05 p. 1)

Remarkably 67 percent of the stranding of from was associated with the Ø-relative clause.

(16) A dialect an Urhobo speaks indicates the kingdom he hails from. (AHum_09 p. 1)

Instances of PS in -ing participle, comparative, wh-relative, wh-questions, and that-clauses are provided in that order as follows.

(17a) ....and you also have the option of signing up with an online web host with easy-to-use web creating tools. (PTec_18 p. 1)

(17b) It shows an artist who is at home with the ideals of the society and what it stands for. (PHum_04 p. 1)

(17c) Aliyu Amusu has only one leg--a victim of childhood disease which he doesn't know of. (PSsc_12 p. 2)

(17d) In conclusion, we ask, what are the Nigerian reforms introduced by the government ultimately for? (AHum_09 p. 4)

(17e) ...he did not join them to scavenge the oil waste dump that they have turned the country into. (PHum_12 p. 1)

As the single most stranded form up featured four times each in the two obligatory contexts of to-infinitive and passive clauses and once each in Ø-relative and -ing (See (17a)) clauses.

(18a) ...it's possible to sign up with a web host with C panel for low monthly fee (PTec_18 p. 1)

(18b) To fill this critical gap, services that benefit both mother and child need to be scaled up, as the health of the mother is closely linked to that of her new born. (PSsc_06 p. 4)

(18c) And what will be left--hapless Nigerians will presumably be put up for privatization, won't they? (AHum_09 p. 1)

\subsubsection{The Collocating Verb Lexemes}

Only a brief comment on the collocating verb lexemes can be afforded because of their heterogeneity and because of space constraint. The 54 verb lexemes collocated with 15 prepositional forms 64 times as already seen. This gives a mean co-occurrence of 3.6 verb lexemes per form. One preposition that exceeded this mean was $t o$. It indeed was stranded after six different verb lexemes, which attests to its versatility. But prepositions do not seem to enter into collocation with just any verb, as some verbs so naturally enjoy the company of certain prepositional forms that their collocation can easily be described as obligatory. Thus, the verb lexeme attend keeps the company of preposition to in the same way as come/from, hail/from, bring /up, and sign/up, and 
account/ for go together (See Table 4). The verb-preposition combination frolicked with and the single instance of coordinated prepositions stranded before a verb of motion serve as illustration. Notice the presence of the relative pronoun whom in (19a). Notice also that the coordinated prepositions in (19b) are in semantic opposition with each other and that the coordinating conjunction indicates alternative.

(19a) Precious Anyanwu in Khadijat, talked of a girl, the daughter of a palm wine seller whom the palm wine tapper frolicked with as a child... (PHum_17 p. 1)

(19b) According to him, there are appliances, lights, computers that can be turned off or on low to conserve energy. (PTec_31 p. 2)

4.2.4 Preposition Stranding in Academic and Popular Writing

Preposition stranding was over two times more frequent in PW than in AW, which posted 44 and 20 occurrences respectively, translating to ratio 2.15:1 in favour of PW. With reference to text types PS was highest in PHum and PTec (14 and 12 respectively) and lowest in ANsc and ASsc (1 each). According to Quirk et al. (1985, p. 684), PS is generally frowned upon in formal English. Yet the genres AW and PW are both samples of formal variety of language from all indications. So why did PS occur at all and why was it more frequent in PW than in AW?

Beginning with the second part of the question, AW is evidently considered more formal and PW less formal when placed on a scale of formality. Producers and consumers of AW are professional academics and researchers with the highest level of education possible. In the sub-corpus examined all the contents of AW were excerpted from published research articles in learned journals or books, which have specified norms for language and presentation that are rigidly adhered to. In contrast, while the original authors of the contents found in PW may also be highly educated researchers as evident in the acknowledgements (e.g., 13i), most of the "visible" writers and the target audience may not necessarily be. As inferable from the texts, some are journalists reporting from some public lecture or seminar (Consider: He explained that climate change challenges will increase desertification...PNsc_12 p. 3) and the general public respectively.

That PS was recorded at all could be evidence that Traditional Grammar's prescriptive rules are fast being disregarded for what is considered more natural English. Hoffmann (2011, p. 78), quoting Daniel, Mckeo and Bernstein (1998, p. 309), noted that PP is not a natural option in English. Indeed 75 percent of PS in AW and 58 percent in PW were in obligatory contexts; they occurred in to-infinitive and passive clauses only. This leaves 25 percent of PS in AW and 42 percent in PW occurring as a result of style preference, which is instructive. It proves that there is a marked difference between AW and PW in terms of degree of formality. Moreover, it is an indication that most writers consciously avoided stranding prepositions, a deliberate effort which seemed more pronounced in AW than in PW. On the whole, 65 percent of PS occurred in obligatory contexts while 35 percent featured in non-obligatory contexts. Stranding was highest in Humanities (27 or 41 percent), with Technology (17 or 29 percent), Social Sciences (12 or 19 percent), and Natural Sciences ( 7 or 9 percent) following in that order.

\subsection{Doubling}

Two cases of double preposition placement in the same clause were recorded. The co-occurrence of PP and PS is a clear indication of error of usage similar to that reported by Hoffmann (2011) in his Kenyan data.

(20a) ...the negative side of deregulation on which so much money is spent on (AHum_09 p. 1)

(20b) ...from an economy driven by mass labour on economy in (sic) which advanced companies rely on. (ASsc_01 p. 3)

The other type of error involves wrong choice of preposition. Given the antecedent noun in (20c), in would have been a more appropriate form.

(20c) This is the daily sunshine hours from which drying will take place. (ATec_01 p.3)

Unlike in Hoffmann's Kenyan data, all three participants implicated here are academics. The writer of (20a) is a male Efik while that of (20b) is a male Yoruba. Information on the gender and ethnic/linguistic background of that of (20c) is however unavailable.

\subsection{Preposition Pied Piping and Stranding Compared}

This comparison of PP and PS in AW and PW excludes doubling, which means the working data comprises 176 tokens. It is in four main parts as follows. 


\subsubsection{Frequency Distribution of Pied Piping and Stranding}

As preposition placement options PP and PS behaved differently in terms of frequency of occurrence in the sub-corpus. To begin with, PP was 1.75 times more frequent than PS since it featured 112 times (64 percent) whereas PS manifested 64 times (36 percent). Pied piping was dominant over stranding in AW, where it accounted for 78 percent (68 occurrences) of that genre's data as opposed to the 22 percent (20 occurrences) of PS. Though evenly distributed in PW (44 each), they differed with respect to the individual text types. In PNsc PP was almost twice as frequent, a trend that was reversed for PS in PTec. Preposition stranding was virtually non-existent in ANsc and ASsc, but it recorded about the same rate as PP in AHum and PSsc.

The difference in formality between AW and PW severally referred to above may explain the disparity recorded in the frequency of PP and PS. Academic Writing is more formal than PW; it therefore manifests more PP and less PS. In contrast, PW permits more PS and less PP because it is less formal. As already rationalised above, the fact that prepositions were stranded at all in non-obligatory contexts provides evidence that prescriptivism may be losing its firm grip even on some of the most acclaimed crop of careful writers. The L2 factor that sometimes impedes on proper usage should also not be undermined. Producers of the texts analysed are highly educated Nigerian L2 users of English, who might have been caught between sticking to the old norm and the dictates of modernity. The revelation that the rule against stranding itself is an imposition from Latin and runs contrary to the structure of English provides insights into the pattern of usage observed in this study. The L1 backgrounds of a significant 31 percent (40) of the writers (participants) were unindicated in the ICE-Nigeria document. Even if all were made available, contrastively finding explanations for the results obtained would drift the study far afield from its focus. It has however been reported that Yoruba has both preposition placement options and that there are PS only prepositions, PP only prepositions, and propositions that can both be pied-piped and stranded (Ajayi, 2019).

\subsubsection{Clause Types}

Of the eight syntactic contexts in which preposition placement took place, the wh-relative clause was the most frequent. It accommodated all the PP cases and 6 of PS, bringing the total to 118 (67 percent). So the $w h$-relative clause was the dominant clause type for preposition placement and PP was the placement option. This finding is in accord with the report earlier referred to that the $w h$-relative clause is the favourite site for preposition placement generally. Genre-wise, the wh-relative clause was more in AW (68 or 58 percent) than in PW (50 or 42 percent). Since PP was restricted to the $w h$-relative clause, it implies that the remaining sites yet to be accounted for are for PS only. Preposition stranding featured largely in to-infinitive (21) and passive (15) clauses, and was thinly distributed in $w h$-question, -ing participle and comparative clauses. It was low occurring in relative clauses, where its 17 cases represent 13 percent of the 129 instantiations. Remarkably all stranding involving the wh-relative clause was recorded in PW. Table 7 displays more details.

Table 7. Comparative frequency of preposition pied piping and stranding in clause types relative to genres

\begin{tabular}{|c|c|c|c|c|c|c|c|c|c|}
\hline \multirow[b]{2}{*}{$\mathrm{S} / \mathrm{N}$} & \multirow[b]{2}{*}{ Clause Types } & \multicolumn{3}{|l|}{ PP } & \multicolumn{3}{|l|}{ PS } & \multirow[b]{2}{*}{ Grand Total } & \multirow[b]{2}{*}{$\%$} \\
\hline & & AW & PW & Sum & AW & PW & Sum & & \\
\hline 1. & $W h$-Relative & 68 & 44 & 112 & 0 & 6 & 6 & 118 & 67 \\
\hline 2. & To-infinitive & 0 & 0 & 0 & 8 & 13 & 21 & 21 & 12 \\
\hline 3. & Passive & 0 & 0 & 0 & 6 & 9 & 15 & 12 & 7 \\
\hline 4. & Ø-Relative & 0 & 0 & 0 & 3 & 4 & 7 & 7 & 4 \\
\hline 5. & That-Relative & 0 & 0 & 0 & 1 & 3 & 4 & 4 & 2.3 \\
\hline 6. & -ing Participle & 0 & 0 & 0 & 0 & 4 & 4 & 4 & 2.3 \\
\hline 7. & Comparative & 0 & 0 & 0 & 0 & 4 & 4 & 4 & 2.3 \\
\hline 8. & Wh-Question & 0 & 0 & 0 & 1 & 1 & 2 & 2 & 1.14 \\
\hline \multirow[t]{3}{*}{9.} & Exclamative & 0 & 0 & 0 & 0 & 0 & 0 & 0 & 0 \\
\hline & Total & 68 & 44 & 112 & 20 & 44 & 64 & 176 & 100 \\
\hline & $\%$ & 61 & 39 & 64 & 31 & 69 & 36 & 100 & \\
\hline
\end{tabular}

\subsubsection{Prepositional Forms and their Frequency in Pied Piping and Stranding}

Twenty-five prepositional forms were either pied-piped (20) or stranded (15) 176 times in the 160 246-word sub-corpus, which gives a frequency per million words(pmw) of 1 098. Of this number 10 featured as pied-piped forms only (e.g., within), 5 occurred as stranded forms only (e.g., off), while 10 operated as pied-piped and stranded forms (e.g., from and by). Preposition in was the most frequent, featuring 40 times representing 23 
percent of the data and occurring at a frequency of $250 \mathrm{pmw}$. The closest form of posted 29 at $156 \mathrm{pmw}$. Six prepositions featured only once each (e.g., among). These and many more facts are exposed in Table 8.

Table 8. Total spectrum of pied-piped and stranded prepositions in academic and popular writing

\begin{tabular}{|c|c|c|c|c|c|c|c|c|c|c|}
\hline \multirow[t]{2}{*}{$\mathrm{S} / \mathrm{N}$} & \multirow[t]{2}{*}{ Preps } & \multicolumn{3}{|c|}{ Pied-Piped } & \multicolumn{3}{|c|}{ Stranded } & \multicolumn{2}{|l|}{ Grand } & \multirow{2}{*}{$\begin{array}{l}\text { Freq. } \\
\text { pmw }\end{array}$} \\
\hline & & AW & PW & Sum & AW & PW & Sum & Total & $\%$ & \\
\hline 1. & in & 19 & 17 & 36 & 1 & 3 & 4 & 40 & 23 & 250 \\
\hline 2. & of & 8 & 9 & 17 & 1 & 2 & 3 & 20 & 11.4 & 125 \\
\hline 3. & with & 5 & 2 & 7 & 5 & 4 & 9 & 16 & 9.1 & 100 \\
\hline 4. & from & 5 & 3 & 8 & 2 & 4 & 6 & 14 & 8 & 87.4 \\
\hline 5. & to & 3 & 1 & 4 & 3 & 4 & 7 & 11 & 6.3 & 69 \\
\hline 6. & for & 3 & 2 & 5 & 2 & 4 & 6 & 11 & 6.3 & 69 \\
\hline 7. & up & 0 & 0 & 0 & 0 & 3 & 7 & 10 & 5.7 & 62 \\
\hline 8. & through & 5 & 1 & 6 & 1 & 2 & 3 & 9 & 5.1 & 56 \\
\hline 9. & on & 4 & 1 & 5 & 0 & 4 & 4 & 9 & 5.1 & 56 \\
\hline 10. & at & 1 & 3 & 4 & 0 & 0 & 0 & 4 & 2.3 & 25 \\
\hline 11. & by & 3 & 0 & 3 & 0 & 1 & 1 & 4 & 2.3 & 25 \\
\hline 12. & out of & 4 & 0 & 4 & 0 & 0 & 0 & 4 & 2.3 & 25 \\
\hline 13. & without & 1 & 2 & 3 & 0 & 0 & 0 & 3 & 1.7 & 19 \\
\hline 14. & upon & 0 & 0 & 0 & 1 & 2 & 3 & 3 & 1.7 & 19 \\
\hline 15. & within & 3 & 0 & 3 & 0 & 0 & 0 & 3 & 1.7 & 19 \\
\hline 16. & off & 0 & 0 & 0 & 1 & 2 & 3 & 3 & 1.7 & 19 \\
\hline 17. & about & 0 & 0 & 0 & 0 & 3 & 3 & 3 & 1.7 & 19 \\
\hline 18. & during & 1 & 1 & 2 & 0 & 0 & 0 & 2 & 1.14 & 13 \\
\hline 19. & into & 0 & 0 & 0 & 1 & 0 & 1 & 1 & 0.6 & 6.24 \\
\hline 20. & below & 1 & 0 & 1 & 0 & 0 & 9 & 1 & 0.6 & 6.24 \\
\hline 21. & after & 1 & 0 & 1 & 0 & 0 & 0 & 1 & 0.6 & 6.24 \\
\hline 22. & among & 0 & 1 & 1 & 0 & 0 & 0 & 1 & 0.6 & 6.24 \\
\hline 23. & across & 0 & 0 & 0 & 0 & 1 & 1 & 1 & 0.6 & 6.24 \\
\hline 24. & around & 0 & 1 & 1 & 0 & 0 & 0 & 1 & 0.6 & 6.24 \\
\hline \multirow[t]{3}{*}{25.} & by means of & 1 & 0 & 1 & 0 & 0 & 0 & 1 & 0.6 & 6.24 \\
\hline & Total & 68 & 44 & 112 & 20 & 44 & 64 & 176 & 100 & 1098 \\
\hline & Freq. pmw & 849 & 549 & 699 & 250 & 549 & 399 & 1098 & & \\
\hline
\end{tabular}

A few prepositions which are of interest because of their frequency of occurrence and because of their syntactic behaviour are examined more closely in the rest of this section. As the form with the highest frequency of occurrence in was fronted in 90 percent (36) and stranded in 10 percent (4) of its total instantiations. Since PP has a total of 112 occurrences and PS has 64, it follows that the probability of its being fronted is 5.2. In other words, in is 5.2 times more likely to occur in pied-piped positions than in stranded positions. Preposition of has 3.19 likelihood of occurring in PP than in PS, being stranded 3 times and pied-piped 17 times. For preposition up its likelihood of occurrence relative to PP is 0 (zero), having been stranded in all its 10 occurrences. Put differently, the occurrence of PS relative to PP with respect to $u p$ is infinitely more. This is true of all the 15 PP-only and PS-only forms in the data. Here, the factor of corpus size must be quickly acknowledged. For instance, if 100 more samples of PP had been selected in respect of up, there could have been a couple of occurrences that would have reduced the probability from infinite to definite. Although this is a mathematical probability, it is doubtful whether there could be a linguistic possibility, at least for $u p$, given reasons bothering on syntax and semantics. Consider these unlikely sequences: *up which *up whom *up whose *up what *up where.

Intra-genre comparison carried out revealed that the rates differed considerably even within the same genre. In AW where 18 prepositions were pied-piped 68 times, for instance, the rate was 3.8 per form whereas the rate of PS per form for the 11 prepositions stranded 20 times was 1.82 . The rate of pied-piped prepositions was also found to differ following inter-genre comparison. It was 3.31 per form in PW in contrast to the 3.8 obtained for AW. This means that the rate of PP per form was much higher than that of PS in AW and that forms were only more slightly pied-piped in AW than in PW. With the 3.31 and 3.1 obtained in respect of PP (13) and PS (14) in $\mathrm{PW}$, it can be inferred that pied-piped prepositions were slightly more concentrated in PW than their stranded counterparts. On PS, the mean of 1.82 per form in AW and 3.1 per form in PW is further proof that PW was more susceptible to PS than AW. 


\section{Conclusion}

This study set out to examine the incidence of preposition pied piping and stranding in academic and popular Nigerian English writing. It is hoped that the objectives have been greatly achieved and that the features exposed by the analysis have deepened our understanding of the subject. What remains is to relate the findings presented above to theory, corpus size, L2 situation, and teaching influence as concluding remarks. This can only be brief.

The choice of Systemic Theory facilitated the systematic and accurate description of the phenomenon investigated in many ways. The proposition that preposition placement is a closed system and that pied piping and stranding are its two mutually exclusive terms was confirmed by the analysis. More significantly, it enabled a detailed account of the terms to be made with respect to their syntactic, semantic and textual patterning. For instance, it can be confidently stated that in which is not just the most frequently occurring pied-piped string but one that takes as its antecedent an abstract noun in 88 percent of its occurrence. A legitimate question can be raised about the corpus size relative to the forms that featured as pied-piped only or as stranded only. It was particularly noted in-text that $u p$ has a mathematical probability of occurring in pied-piped contexts if the sample were to be considerably larger than what was analysed. This is quite hard to imagine linguistically though, given that certain prepositions occur as stranding only. Producers of academic and popular Nigerian English writing are highly Educated Nigerian English users, but the two cases of dual marking of pied piping and stranding and the single incidence of wrong prepositional choice might suggest that they fall short of their Educated British English counterparts. The long tradition of grammar teaching that promotes pied piping for its elegance and despises stranding certainly has some influence on the high incidence of pied piping in comparison with stranding. While teaching influence cannot explain why stranding occurred at all even in formal writing, cognizance must not be lost of the presence of obligatory pied piping and obligatory stranding in preposition placement. Their numbers in the data analysed are not insignificant.

\section{References}

Adejare, R. A. (2020). A corpus-based study of complex prepositions in a non-native English variety. Open Journal of Modern Linguistics, 10(4), 215-259. https://doi.org/10.4236/ojml.2020.104014

Ajayi, J. (2019). Preposition stranding and pied piping in Yoruba focus constructions. MA Thesis, Memorial University of Newfoundland.

Almahameed, Y. S., Ariff, T. N. A., \& Sidek, H. M. (2015). The acquisition of preposition stranding and pied piping in interrogatives by Arab Jordanian EFL speakers. International Journal of Linguistics, 7(4), 16-26. https://doi.org/10.5296/ijl.v7i4.8200

Bamigbade, W. A. (2012). The limit of our liberty with English in Nigeria: The linguistic style of six Nigerian conference flyers. Journal of the Nigerian English Studies Association (JNESA), 25(2), 165-182.

Berry, M. (1975). Introduction to systemic linguistics 1: Structure and systems. London: B.T. Batsford.

Cappele, B. (2001). Is out of always a preposition? Journal of English Linguistics, 29(4), 315-328, December 2001. Uploaded 20 May 2015. https://doi.org/10.1177/00754240122005468.

Christophersen, S., \& Sandved, A. O. (1969). An advanced English grammar. London: Macmillan \& Co Ltd.

Eggins, S. (2004). An Introduction to functional linguistics. London: Continuum.

Ekundayo, O. S. B (2014). Prepositional intraference in ESL and its teaching: The educated Nigerian English example. Journal of English Language Teaching, 4(4), 39-49. https://doi.org/10.26634/jelt.4.4.3028

Firth, J. R. (1957). Papers in linguistics: 1934-1951. London: Oxford University Press.

Greenbaum, S., \& Nelson, G. (2002). An introduction to English grammar (2nd ed.). Edinburgh: Pearson Education Limited.

Halliday, M. A. K. (1961). Categories of the theory of grammar. Word (Rpt as Bobbs-Merill Series, No Language 36), 17(3), 241-292. https://doi.org/10.1080/00437956.1961.11659756

Halliday, M. A. K. (1985). An introduction to functional grammar. London: Edward Arnold.

Halliday, M. A. K., \& Matthiessen, C. M. I. M. (2004). An introduction to functional grammar (3rd ed.). London: Hodder Arnold.

Hoffmann, T. (2005). Variable vs categorical effects: Preposition pied piping and stranding in British English relative clauses. Journal of English Linguistics, 33(3), 257-297. https://doi.org/10.1177/0075424205282891

Hoffmann, T. (2007). "I need data which I can rely on": Corroborating empirical evidence on preposition 
placement in English relative clauses. In S. Featherston \& W. Sternefeld (Eds.), Roots: Linguistics in Search of its Evidential Base (pp. 161-183). Berlin: Mouton de Gruyter.

Hoffmann, T. (2008). English relative clauses and Construction Grammar: A topic which preposition placement can shed light on? In G. Trousdale \& N. Gisborne (Eds.), Constructional explanations in English grammar (pp. 77-112). Berlin: Mouton de Gruyter. https://doi.org/10.1515/9783110199178.2.77

Hoffmann, T. (2011). Preposition placement in English: A usage-based approach. Cambridge: Cambridge University Press.

Huddleston, R. (1984). Introduction to the Grammar of English. Cambridge: Cambridge University Press. https://doi.org/10.1017/CBO9781139165785

International Corpus of English-Nigeria. (2015). Retrieved from https://sourceforge./net/projects/ice-nigeria

Jack, D. (2019). Preposition placement in English as a second language. PhD Thesis, Friedrich Schiller University, Jena, Germany.

Jibril, M. (1991). The sociolinguistics of preposition usage in Nigerian English. In J. Chesire (Ed.), English Around the World: Sociolinguistic Perspectives (pp. 519-544). Cambridge: Cambridge University Press, Online publication, June 2012. https://doi.org/10.1017/CBO9780511611889.036

Ovu, B. F. (2018). Locating sources of preposition redundancy in the use of transitive verbs among second language learners of English. Ebonyi Journal of Language and Literary Studies, 1(2), 198-210, April 2018.

Quirk, R., Greenbaum, S., Leech, G. N., \& Svartvik, J. (1985). A comprehensive grammar of the English language. London: Longman.

Radford, A. (2004). English Syntax: An Introduction. Cambridge: Cambridge University Press. https://doi.org/10.1017/CBO9780511841675

Rezai, M. J. (2006). Preposition stranding and pied piping in second language acquisition. Essex Graduate Student Papers in Language and Linguistics, 8(8), 110-128.

Sotiloye, B. S., Bodunde, H. S., \& Olayemi, O. (2015). English language prepositions: An albatross for English language learners in Nigeria. International Journal of English and Literature, 6(6), 103-108, June 2015. https://doi.org/10.5897/IJEL2015.0783

Strang, B. H. M. (1969). Modern English Structure. London: Edward Arnold.

\section{Copyrights}

Copyright for this article is retained by the author, with first publication rights granted to the journal.

This is an open-access article distributed under the terms and conditions of the Creative Commons Attribution license (http://creativecommons.org/licenses/by/4.0/). 